\title{
PICT1 expression is a poor prognostic factor in non-small cell lung cancer
}

\author{
Kyoko Okamura ${ }^{1}$, Koichi Takayama ${ }^{1}$, Kohichi Kawahara ${ }^{2,3}$, Taishi Harada ${ }^{1}$, Miki \\ Nishio ${ }^{3}$, Kohei Otsubo ${ }^{1,3}$, Kayo Ijichi ${ }^{1,4}$, Mikihiro Kohno ${ }^{5}$, Eiji Iwama ${ }^{1,6}$, Akiko Fujii ${ }^{1}$, \\ Keiichi Ota ${ }^{1}$, Takaomi Koga ${ }^{4}$, Tatsuro Okamoto ${ }^{5}$, Akira Suzuki ${ }^{3}$, Yoichi Nakanishi ${ }^{1}$ \\ ${ }^{1}$ Research Institute for Diseases of the Chest, Graduate School of Medical Sciences, Kyushu University, Japan. \\ 2 Department of Molecular Oncology, Graduate School of Medical and Dental Science, Kagoshima University, Japan. \\ ${ }^{3}$ Division of Cancer Genetics, Medical Institute of Bioregulation, Kyushu University, Japan. \\ ${ }^{4}$ Division of Pathophysiological and Experimental Pathology, Department of Pathology, Graduate School of Medical Sciences, \\ Kyushu University, Japan. \\ ${ }^{5}$ Department of Surgery and Science, Graduate School of Medical Sciences, Kyushu University, Japan. \\ ${ }^{6}$ Faculty of Medical Sciences, Department of Comprehensive Clinical Oncology, Kyushu University, Japan. \\ Correspondence to: Koichi Takayama, email: koichi-t@kokyu.med.kyushu-u.ac.jp
}

Keywords: PICT1; TP53; lung cancer; lymphatic invasion; GLTSCR2

Received: March 19, $2014 \quad$ Accepted: May 25, $2014 \quad$ Published: May 25, 2014

This is an open-access article distributed under the terms of the Creative Commons Attribution License, which permits unrestricted use, distribution, and reproduction in any medium, provided the original author and source are credited.

\section{ABSTRACT:}

PICT1 is a key regulator of the MDM2-TP53 pathway. High mRNA expression levels of PICT1 are associated with poor prognosis in several cancers with wild-type TP53. In this study, we identified the PICT1 protein expression profile in non-small cell lung cancer (NSCLC) with wild-type TP53 in the nucleolus and cytoplasm, and revealed the relationship between PICT1 expression and patient clinicopathological factors. PICT1 expression in the tumor cells of 96 NSCLC patients with wild-type TP53 was evaluated by immunohistochemistry. Forty-three of 96 (44.8\%) NSCLC samples were positive for nucleolar PICT1, while 40/96 (41.7\%) NSCLC samples were positive for cytoplasmic PICT1. There was no correlation between nucleolar PICT1 expression and clinicopathological factors. However, cytoplasmic PICT1 expression was significantly correlated with sex, smoking history, differentiation, lymphatic invasion and pathological stage. In multivariate analysis, lymphatic invasion was significantly associated with cytoplasmic PICT1 expression (hazard ratio: 5.02, $P$ $=0.026)$. We scrutinized PICT1 expression in samples of NSCLC with wild-type TP53, and showed a correlation between cytoplasmic PICT1 expression and several clinicopathological factors in these patients. Our results indicate that cytoplasmic PICT1 expression is a poor prognostic factor and is associated with tumor progression via lymphatic invasion in these patients.

\section{INTRODUCTION}

Lung cancer is a common cause of cancer-related death worldwide. Patients with early-stage lung cancer who undergo curative surgical resection often die from recurrent disease or distant metastases. The long-term survival rate for lung cancer patients remains low [1]. Thus, personalized and targeted lung cancer therapy dependent on the characteristics of each patient is urgently required.
TP53 activation by ribosomal biogenesis stress is important for tumor suppression [2]. Protein interacting with carboxylterminus-1 (PICT1) gene, also called glioma tumor suppressor candidate region gene 2 (GLTSCR2), is located at human chromosome $19 \mathrm{q} 13.32$, which is frequently altered in human tumors [3]. We previously identified that PICT1 is an important regulator that acts primarily through ribosomal protein 11 (RPL11) and murine double minute 2 (MDM2) to inhibit TP53 responses against nucleolar stress $[4,5]$. PICT1 binds to 
RPL11 in the nucleolus and prevents it from interacting with MDM2, thus blocking TP53 accumulation and activation. We also showed that low PICT1 expression was associated with better prognosis in colorectal tumors, esophageal tumors, hepatocellular carcinomas and gastric cancers with wild-type TP53 [4, 6, 7]. Thus, PICT1 is a useful prognostic marker for these cancers [4]. However, PICT1 has been considered as a suppressor of tumor development [8-10]. Overexpression of GLTSCR2 induced phosphatase and tensin homolog (PTEN)dependent apoptotic cell death in glioblastoma cells [10]. Knockdown of PICT1 promoted cell proliferation and anti-apoptosis [11]. Low PICT1 expression in astrocytic glial tumors and ovarian cancers was correlated with high malignant progression $[8,9,12]$. There are no reports available concerning PICT1 expression in lung cancer, and its relationship with clinical factors in this cancer type is unknown.

In this study, we investigated the expression of PICT1 in surgically resected non-small cell lung cancers (NSCLC) without TP53 mutation using immunohistochemistry. We identified a relationship between PICT1 expression and clinicopathological variables in NSCLC with wild-type TP53.

\section{RESULTS}

\section{PICT1 expression in lung cancer tissue}

The patients' characteristics are summarized in Table 1. Clinicopathological factors, including age, sex, smoking history, differentiation, vascular invasion, lymphatic invasion, pleural invasion, $\mathrm{T}$ status, $\mathrm{N}$ status, pathological stage, epidermal growth factor receptor (EGFR) mutation status (41 patients with sensitive mutations, 49 patients without mutations, six patients with unknown mutational status) and histological subtype, were evaluated. There were 53 males and 43 females, with a mean age of 67.7 \pm 9.3 years.

Representative images of immunohistochemical staining of PICT1 expression in the nucleolus or cytoplasm are shown in Figure 1. Nucleolar or cytoplasmic staining was evaluated independently. Forty-three of 96 (44.8\%) NSCLC samples were positive for PICT1 in the nucleolus. Forty of 96 (41.7\%) NSCLC samples were positive for cytoplasmic PICT1. Seventeen patients were positive for both nucleolar and cytoplasmic PICT1, while 26 patients were positive in the nucleolus only, 23 patients in only the cytoplasm, and 30 patients were negative in both the nucleolus and cytoplasm (Table 2). There was no significant correlation between nucleolar and cytoplasmic PICT1 expression using chi-square tests $(P=0.703)$.

\section{Correlations between PICT1 expression and clinicopathological factors in NSCLC}

The relationship between the clinicopathological factors of NSCLC patients with wild-type TP53 and PICT1 expression are shown in Table 1. Nucleolar and cytoplasmic PICT1 expression were determined to be positive or negative. There was no correlation between nucleolar PICT1 expression and clinicopathological factors. However, cytoplasmic PICT1 expression was significantly correlated with sex $(P=0.013)$, smoking history $(P=0.005)$, differentiation $(P=0.001)$, lymphatic invasion $(P=0.012)$ and pathological stage $(P=0.012)$.

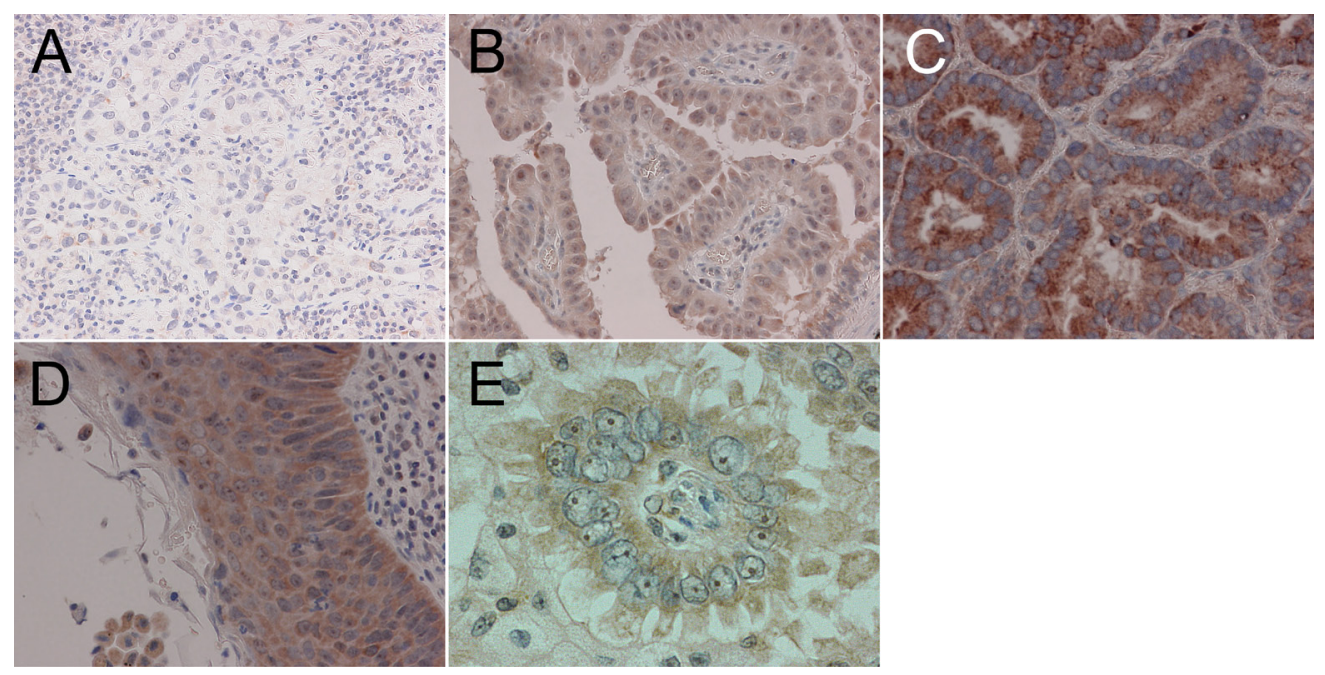

Figure 1: Nucleolar and cytoplasmic PICT1 expression in non-small cell lung cancer. (A) Negative nucleolar and cytoplasmic PICT1 staining in adenocarcinoma (magnification 200×). (B) Positive nucleolar and cytoplasmic PICT1 staining in adenocarcinoma (200×). (C) Negative nucleolar and positive cytoplasmic PICT1 staining in adenocarcinoma (200×). (D) Positive nucleolar and cytoplasmic PICT1 staining in squamous cell carcinoma $(200 \times)$. (E) Positive nucleolar PICT1 staining in adenocarcinoma $(1200 \times)$. 
Table 1. Correlation between PICT1 expression and clinicopathological factors in 96 non-small cell lung cancer samples (wild-type TP53).

\begin{tabular}{|c|c|c|c|c|c|c|c|c|}
\hline \multirow{2}{*}{\multicolumn{2}{|c|}{ Factors }} & \multirow[b]{2}{*}{$\begin{array}{c}\text { Total } \\
\text { patients } \\
n=96\end{array}$} & \multicolumn{2}{|c|}{ nucleolus } & \multirow[b]{2}{*}{$P$ value } & \multicolumn{2}{|c|}{ cytoplasm } & \multirow[b]{2}{*}{$P$ value } \\
\hline & & & $\begin{array}{l}\text { PICT1- } \\
\text { positive } \\
n=43 \\
(\%)\end{array}$ & $\begin{array}{c}\text { PICT1- } \\
\text { negative } \\
n=53 \\
(\%)\end{array}$ & & $\begin{array}{c}\text { PICT1- } \\
\text { positive } \\
n=40 \\
(\%)\end{array}$ & $\begin{array}{c}\text { PICT1- } \\
\text { negative } \\
\mathrm{n}=56 \\
(\%)\end{array}$ & \\
\hline \multirow[t]{2}{*}{ Age } & $<70$ & 55 & $24(44)$ & $31(56)$ & 0.792 & $25(45)$ & $30(55)$ & 0.382 \\
\hline & $\geq 70$ & 41 & $19(46)$ & $22(54)$ & & $15(37)$ & $26(63)$ & \\
\hline \multirow[t]{2}{*}{ Sex } & Male & 53 & $23(43)$ & $30(57)$ & 0.760 & $28(53)$ & $25(47)$ & $0.013 *$ \\
\hline & Female & 43 & $20(47)$ & $23(53)$ & & $12(28)$ & $31(72)$ & \\
\hline \multirow[t]{2}{*}{ Smoking history } & Smoker & 56 & $26(46)$ & $30(54)$ & 0.703 & $30(54)$ & $26(46)$ & $0.005 *$ \\
\hline & Never smoked & 40 & $17(42)$ & $23(58)$ & & $10(25)$ & $30(75)$ & \\
\hline \multirow[t]{2}{*}{ Differentiation } & Well & 46 & $20(43)$ & $26(57)$ & 0.804 & $11(24)$ & $35(76)$ & $0.001 *$ \\
\hline & Moderately + poorly & 50 & $23(46)$ & $27(54)$ & & $29(58)$ & $21(42)$ & \\
\hline \multirow[t]{2}{*}{ Vascular invasion } & Absent & 71 & $34(48)$ & $37(52)$ & 0.301 & $26(37)$ & $45(63)$ & 0.093 \\
\hline & Present & 25 & $9(36)$ & $16(64)$ & & $14(56)$ & $11(44)$ & \\
\hline \multirow[t]{2}{*}{ Lymphatic invasion } & Absent & 84 & $38(45)$ & $46(55)$ & 0.816 & $31(37)$ & $53(63)$ & $0.012^{*}$ \\
\hline & Present & 12 & $5(42)$ & $7(58)$ & & $9(75)$ & $3(25)$ & \\
\hline \multirow[t]{2}{*}{ Pleural invasion } & Absent (P0) & 82 & $38(46)$ & $44(54)$ & 0.456 & $31(38)$ & $51(62)$ & 0.065 \\
\hline & Present (P1-3) & 14 & $5(36)$ & $9(64)$ & & $9(64)$ & $5(36)$ & \\
\hline \multirow[t]{4}{*}{$\Upsilon$ status } & $\mathrm{T} 1$ & 62 & $26(42)$ & $36(58)$ & 0.216 & $22(35)$ & $40(65)$ & 0.240 \\
\hline & $\mathrm{T} 2$ & 28 & $16(57)$ & $12(43)$ & & $14(50)$ & $14(50)$ & \\
\hline & $\mathrm{T} 3$ & 5 & $1(20)$ & $4(80)$ & & $3(60)$ & $2(40)$ & \\
\hline & $\mathrm{T} 4$ & 1 & $0(0)$ & $1(100)$ & & $1(100)$ & $0(0)$ & \\
\hline \multirow[t]{3}{*}{ N status } & No & 86 & $40(47)$ & $46(53)$ & 0.577 & $33(38)$ & $53(62)$ & 0.085 \\
\hline & $\mathrm{N} 1$ & 6 & $2(33)$ & $4(67)$ & & $5(83)$ & $1(17)$ & \\
\hline & $\mathrm{N} 2$ & 4 & $1(25)$ & $3(75)$ & & $2(50)$ & $2(50)$ & \\
\hline \multirow[t]{2}{*}{ Pathological stage } & $\mathrm{I}+\mathrm{II}$ & 89 & $41(46)$ & $48(54)$ & 0.361 & $34(38)$ & $55(62)$ & $0.012^{*}$ \\
\hline & III+IV & 7 & $2(29)$ & $5(71)$ & & $6(86)$ & $1(14)$ & \\
\hline \multirow[t]{3}{*}{ EGFR mutation } & No mutation & 49 & $19(39)$ & $30(61)$ & 0.237 & $24(49)$ & $25(51)$ & 0.096 \\
\hline & With mutation & 41 & $21(51)$ & $20(49)$ & & $13(32)$ & $28(68)$ & \\
\hline & Unknown & 6 & $3(50)$ & $3(50)$ & & $3(50)$ & $3(50)$ & \\
\hline Histological & Adenocarcinoma & 86 & $37(43)$ & $49(57)$ & 0.308 & $33(38)$ & $53(62)$ & 0.056 \\
\hline subtype & Squamous cell carcinoma & 10 & $6(60)$ & $4(40)$ & & $7(70)$ & $3(30)$ & \\
\hline
\end{tabular}

${ }^{*} P<0.05$

Lung cancer tissue from males, smokers, moderate or poor differentiation, positive lymphatic invasion and advanced stage showed significantly higher positive rates of cytoplasmic PICT1 expression. In the histological subgroup analysis, squamous cell carcinoma tissue had a tendency to show higher positive rates of both nucleolar and cytoplasmic PICT1 expression than adenocarcinoma tissues (Figure 1D and Table 1), although this was not statistically significant.

Multivariate analysis using a logistic regression model (Table 3) with factors proven to be significant in the chi-square analysis revealed that only lymphatic 
Table 2. Relationship between nucleolar and cytoplasmic PICTI expression.

\begin{tabular}{cccc}
\hline & $\begin{array}{c}\text { cytoplasm } \\
\text { PICT1-positive } \\
(\mathrm{n}=40)\end{array}$ & $\begin{array}{c}\text { cytoplasm } \\
\text { PICT1-negative } \\
(\mathrm{n}=56)\end{array}$ & $P$ value \\
\hline $\begin{array}{c}\text { nucleolus } \\
\text { PICT1-positive } \\
(\mathrm{n}=43)\end{array}$ & 17 & 26 & \\
$\begin{array}{c}\text { nucleolus } \\
\text { PICT1-negative } \\
(\mathrm{n}=53)\end{array}$ & 23 & & 0.703 \\
\hline
\end{tabular}

Table 3. Multivariate analysis of the association between clinicopathological factors and cytoplasmic PICT1 expression.

\begin{tabular}{lccc}
\hline & \multicolumn{3}{c}{ PICT1 expression in cytoplasm } \\
Factors & Hazard ratio & $95 \%$ CI & $P$ value \\
\hline Sex (male/female) & 0.45 & $0.14-1.37$ & 0.159 \\
Smoking history & 1.96 & $0.64-6.30$ & 0.240 \\
Differentiation (well vs moderate/poor) & 2.63 & $0.99-7.15$ & 0.053 \\
Lymphatic invasion & 5.02 & $1.20-27.51$ & $0.026^{*}$ \\
Pathological stage (I+II vs III+IV) & 5.82 & $0.85-118.4$ & 0.077 \\
\hline$* P<0.05$ & & &
\end{tabular}

Abbreviation: CI , confidence interval

invasion was significantly associated with cytoplasmic PICT1 expression (hazard ratio: HR 5.02, 95\% C.I. 1.20$27.51, P=0.026$ ). Lung cancer tissue (wild-type TP53) with positive lymphatic invasion had a significantly higher positive rate of cytoplasmic PICT1 expression (Figure 2).

\section{DISCUSSION}

This study scrutinized the expression of PICT1 in the nucleoli and cytoplasm of NSCLC cells with wild-type TP53. PICT1 has been known to be a nucleolar protein; however, in our study many NSCLC tissues expressed PICT1 not only in the nucleoli but also in the cytoplasm. Although there was no correlation between nucleolar PICT1 expression and clinicopathological factors in NSCLC patients with wild-type TP53, cytoplasmic PICT1 expression was significantly associated with several clinicopathological factors (male, smoker, moderate or poor differentiation, advanced stage and lymphatic invasion) in these patients. It is well known that the mutation rate of TP53 is particularly high in current smokers [13-15]. In this study, positive cytoplasmic PICT1 expression was associated with smoking in

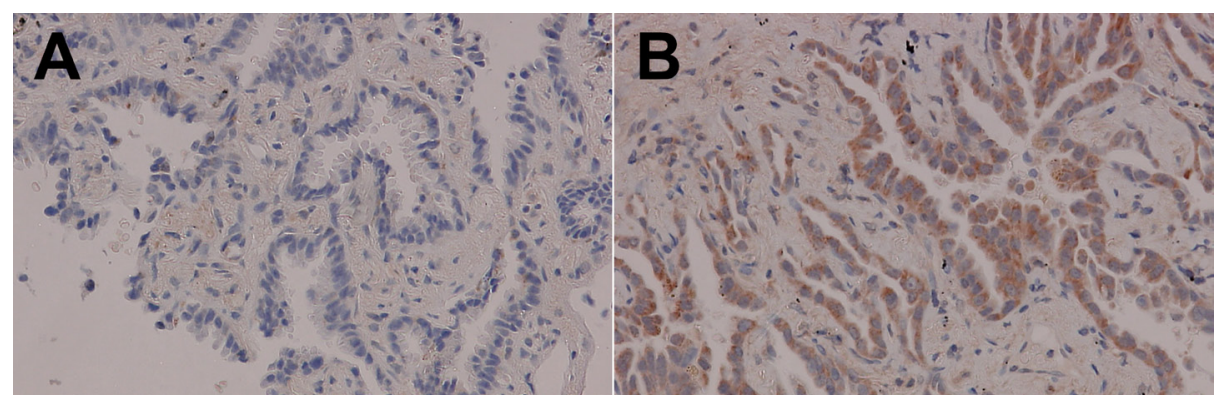

Figure 2: Cytoplasmic PICT1 expression in adenocarcinoma with lymphatic invasion. Lung cancer tissue with lymphatic invasion had a significantly higher rate of positive cytoplasmic PICT1 expression than samples without lymphatic invasion. (A) Negative cytoplasmic PICT1 in adenocarcinoma with negative lymphatic invasion (200×). (B) Positive cytoplasmic PICT1 staining in adenocarcinoma with positive lymphatic invasion $(200 \times)$. 
NSCLC patients with wild-type TP53. Other factors, such as moderate or poor differentiation and advanced stage, were considerably poor prognostic factors. Multivariate analysis revealed that lymphatic invasion was the sole factor associated with cytoplasmic PICT1 expression; lymphatic vessel invasion has previously been considered an independent poor prognostic factor in surgically managed NSCLC [16-19]. Furthermore, TP53 mutation or overexpression was demonstrated to be an indicator of poor prognosis in NSCLC [15, 20, 21]. Although the role of PICT1 in lymphatic invasion by tumor cells is not known, our results suggested the possibility that cytoplasmic PICT1 is associated with malignant behavior in NSCLC patients with wild-type TP53.

Although the expression of PICT1 in some tumors has been investigated immunohistochemically, it is controversial whether PICT1 is associated with malignant potential in cancer cells $[8,22]$. PICT1 was previously considered a suppressor of tumor development [8-10], and low PICT1 expression in astrocytic glial tumors and ovarian cancers was correlated with high malignant progression $[8,9,12]$. This is the first report of PICT1 expression in NSCLC. We previously reported that PICT1 was a potential regulator of the MDM2-TP53 pathway and promoted tumor progression [4]. In fact, low PICT1 mRNA expression was associated with better prognosis in colorectal tumors, esophageal tumors, hepatocellular carcinomas and gastric cancers with wild-type TP53, therefore PICT1 was considered to be a useful prognostic marker for these cancers $[4,6,7]$. Together with our previous report and current study, we speculate that PICT1 expression might be associated with the malignant potential and tumor progression of NSCLC.

We previously reported the shorter survival in high PICT1 mRNA level patients with several cancers, and PICT1 thought to be a key regulator of tumor progression, $[4,6,7]$. However, the relationship between PICT1 protein localization and clinicopathological factors in patients with cancers has not been known. So, this is also the first report about the association between PICT1 protein expression and clinicopathological factors in patients with cancers. We reported that there were no significant differences between high and low PICT1 expression in several clinichopathological factors of hepatocellular carcinoma patients with wild type TP 53[6]. In gastric cancer patients with wild-type TP53, PICT1 expression was significantly associated with tumor depth[7]. There were no significant association between lymphatic invasion and PICT1 level in these patients[7]. In NSCLC with wild type TP53, we found that cytoplasmic PICT1 expression was significantly associated with several clinichopathological factors.

PICT1 binds to RPL11 in the nucleolus and prevents it from interacting with MDM2, thus blocking TP53 accumulation and activation [4]. Upon nucleolar stress, ribosomal protein RPL5, RPL11, RP23 and RPS7 is released from the nucleolus, binds MDM2 and activates TP53 [23-27]. We previously reported that although most of the PICT1 located in nucleolus, some of them also located in cytoplasm[4]. In this study, cytoplasmic PICT1 expression was correlated with several clinicopathological factors, but the role of this subcellular localization pattern is not yet known. Bursac et al. reported recently that upon exposure of cells to various ribosomal stressors, RPL5 and RPL11 accumulate in the ribosome-free fraction where they specially bind MDM2 [28]. A significant increase in the amount of ribosome-free RPL11 in the cytoplasm was observed, and TP53 activation might be required in response to ribosomal biogenesis stressors [28]. Another ribosomal protein, RPS27L regulate p53 function. RPS $27 \mathrm{~L}$ is mainly localized in cytoplasm under unstressed condition, but RPS27L is shuttled to nucleus, upon DNA damage and ribosomal stress, where it colocalized with MDM2[29]. Although further study will be required to address the significance of cytoplasmic PICT1 protein expression, together with results of this study, these predictions raise the possibility that PICT1 in the cytoplasm might also be important in tumor progression to control TP53 accumulation by regulating localization of ribosomal protein in the cytosolic ribosomal fraction, as well as nucleolar PICT1 to retain RPL11 in the nucleolas.

In conclusion, we scrutinized PICT1 expression in samples of NSCLC with wild-type TP53, and showed a potential correlation between cytoplasmic PICT1 expression and several clinicopathological factors in these patients. The results indicated that cytoplasmic PICT1 expression was a significant poor prognostic factor in NSCLC. Our results suggest the possibility that PICT1 promotes tumor progression in NSCLC via lymphatic invasion. Further studies are required to identify the precise role of PICT1 in lung cancer patients. Moreover, TP53 status may be of great value in the choice of chemoradiation therapy, and the TP53 pathway might be a therapeutic target [15]. When this is fully determined, we will have a novel approach with which we can explore personalized and targeted therapy in PICT1-positive lung cancer patients with wild-type TP53.

\section{MATERIALS AND METHODS}

\section{Patients and sample collection}

In this retrospective study, we analyzed specimens from 96 NSCLC patients with wild-type TP53 (86 adenocarcinoma, 10 squamous cell carcinoma) who had undergone surgical resection for lung cancer at the Department of Surgery and Science, Kyusyu University Hospital in Japan, from January 2009 to March 2011.

Surgical specimens were fixed in neutral-buffered 
formaldehyde, and processed for histopathological and immunohistochemical evaluation. Histological subtype of tumors and pathological stage were classified according to the WHO 2004 classification [30] and UICC guidelines of TNM classification (version 7), respectively [31]. This study was approved by the Ethics Committee of Kyusyu University.

\section{Immunohistochemistry}

The Human Protein Atlas site (the project is funded by the Knut \& Alice Wallenberg foundation) detailed the results of PICT1 expression in several malignant tissues. They showed that PICT1 expression was positive in both the cytoplasm and nuclei of lung cancer tissues.

Paraffin sections of surgically resected specimens were routinely deparaffinized and rehydrated [32]. The sections were incubated overnight at $4{ }^{\circ} \mathrm{C}$ with primary rabbit polyclonal antibody against PICT1, GLTSCR2 (PICT1: HPA018999, Sigma-Aldrich), then incubated with secondary antibody conjugated with streptavidinbiotin peroxidase (Histofine SAB-PO kit, Nichirei, Tokyo, Japan), and visualized with 3,3'-diaminobenzidine (DAB). Normal brain section was used as a positive control for PICT1 [8]. Parallel negative controls omitting primary antibody were also prepared, and did not show background (data not shown). All the immunoreactions were separately evaluated by two investigators (K.O. and K.T.) without prior knowledge of patients' clinical records. Nucleolar and cytoplasmic staining were evaluated separately. Tumor cells with brown staining in the nucleolus or cytoplasm were regarded as positive $c f$. Figure 1 .

\section{Mutation spectrum analysis for TP53 gene}

We immediately froze the resected lung cancer tissues in liquid nitrogen. Genomic DNA was extracted from tissue samples. We determined mutational status of TP53 by sequencing a DNA region spanning exons 5 to 9, the area where most TP53 mutations occur as reported previously [33, 34]. Briefly, the DNA fragments were amplified by polymerase chain reaction (PCR) using each primer pair. Mutations in TP53 were detected by PCR direct sequencing of all PCR products with the ABI Prism 310 Genetic Analyzer (Applied Biosystems).

Then we chose all lung cancer tissues without TP53 mutation as being wild-type for TP53, and examined PICT1 expression.

\section{Statistical analysis}

Average scores were expressed as mean \pm standard deviation (SD). Chi-square tests were used to analyze the correlation between clinicopathological factors and PICT1 immunoreactivity. Logistic regression model was used for the multivariate analysis of the association between PICT1 expression and clinicopathological factors proven to be significant in the chi-square test. $P$ values less than 0.05 were considered to be statistically significant. JMP version 9 (SAS Institute, Inc., Cary, NC, USA) software was used for all analyses.

\section{ACKNOWLEDGMENTS}

This study was supported by a research fund from the Research Institute for Diseases of the Chest, and Platform for Drug Discovery, Informatics, and Structural Life Science from the Ministry of Education, Culture, Sports, Science and Technology, Japan.

No potential conflicts of interest were disclosed.

\section{REFERENCES}

1. Siegel R, Naishadham D and Jemal A. Cancer statistics, 2012. CA: a cancer journal for clinicians. 2012; 62(1):1029.

2. Golomb L and Oren M. DePICTing p53 activation: a new nucleolar link to cancer. Cancer cell. 2011; 20(3):283-284.

3. Smith JS, Tachibana I, Pohl U, Lee HK, Thanarajasingam U, Portier BP, Ueki K, Ramaswamy S, Billings SJ, Mohrenweiser HW, Louis DN and Jenkins RB. A transcript map of the chromosome 19q-arm glioma tumor suppressor region. Genomics. 2000; 64(1):44-50.

4. Sasaki M, Kawahara K, Nishio M, Mimori K, Kogo R, Hamada K, Itoh B, Wang J, Komatsu Y, Yang YR, Hikasa H, Horie Y, Yamashita T, Kamijo T, Zhang Y, Zhu Y, et al. Regulation of the MDM2-P53 pathway and tumor growth by PICT1 via nucleolar RPL11. Nature medicine. 2011; 17(8):944-951.

5. Suzuki A, Kogo R, Kawahara K, Sasaki M, Nishio M, Maehama T, Sasaki T, Mimori K and Mori M. A new PICTure of nucleolar stress. Cancer science. 2012; 103(4):632-637.

6. Ishibashi M, Kogo R, Shibata K, Ueo H, Uchi R, Matsumura T, Takano Y, Sawada G, Takahashi Y, Mima K, Kurashige J, Akiyoshi S, Iwaya T, Eguchi H, Sudo T, Sugimachi K, et al. Clinical Significance of PICT1 in Patients of Hepatocellular Carcinoma with Wild-Type TP53. Annals of surgical oncology. 2013.

7. Uchi R, Kogo R, Kawahara K, Sudo T, Yokobori T, Eguchi H, Sugimachi K, Maehama T, Mori M, Suzuki A, Komune $\mathrm{S}$ and Mimori K. PICT1 regulates TP53 via RPL11 and is involved in gastric cancer progression. British journal of cancer. 2013.

8. Kim YJ, Cho YE, Kim YW, Kim JY, Lee S and Park JH. Suppression of putative tumour suppressor gene GLTSCR2 expression in human glioblastomas. The Journal of pathology. 2008; 216(2):218-224. 
9. Merritt MA, Parsons PG, Newton TR, Martyn AC, Webb PM, Green AC, Papadimos DJ and Boyle GM. Expression profiling identifies genes involved in neoplastic transformation of serous ovarian cancer. BMC cancer. 2009; 9:378.

10. Yim JH, Kim YJ, Ko JH, Cho YE, Kim SM, Kim JY, Lee $\mathrm{S}$ and Park JH. The putative tumor suppressor gene GLTSCR2 induces PTEN-modulated cell death. Cell death and differentiation. 2007; 14(11):1872-1879.

11. Okahara F, Itoh K, Nakagawara A, Murakami M, Kanaho Y and Maehama T. Critical role of PICT-1, a tumor suppressor candidate, in phosphatidylinositol 3,4,5-trisphosphate signals and tumorigenic transformation. Molecular biology of the cell. 2006; 17(11):4888-4895.

12. Nakagawa Y, Yoshida A, Numoto K, Kunisada T, Wai D, Ohata N, Takeda K, Kawai A and Ozaki T. Chromosomal imbalances in malignant peripheral nerve sheath tumor detected by metaphase and microarray comparative genomic hybridization. Oncology reports. 2006; 15(2):297303.

13. Kondo K, Tsuzuki H, Sasa M, Sumitomo M, Uyama T and Monden Y. A dose-response relationship between the frequency of p53 mutations and tobacco consumption in lung cancer patients. Journal of surgical oncology. 1996; 61(1):20-26.

14. Mounawar M, Mukeria A, Le Calvez F, Hung RJ, Renard H, Cortot A, Bollart C, Zaridze D, Brennan P, Boffetta P, Brambilla E and Hainaut P. Patterns of EGFR, HER2, TP53, and KRAS mutations of p14arf expression in nonsmall cell lung cancers in relation to smoking history. Cancer research. 2007; 67(12):5667-5672.

15. Mogi A and Kuwano H. TP53 mutations in nonsmall cell lung cancer. Journal of biomedicine \& biotechnology. 2011; 2011:583929.

16. Wang J, Wang B, Zhao W, Guo Y, Chen H, Chu H, Liang X and Bi J. Clinical significance and role of lymphatic vessel invasion as a major prognostic implication in non-small cell lung cancer: a meta-analysis. PloS one. 2012; 7(12):e52704.

17. Shiono S, Abiko $M$ and Sato T. Positron emission tomography/computed tomography and lymphovascular invasion predict recurrence in stage I lung cancers. Journal of thoracic oncology : official publication of the International Association for the Study of Lung Cancer. 2011; 6(1):43-47.

18. Taylor MD, Nagji AS, Bhamidipati CM, Theodosakis N, Kozower BD, Lau CL and Jones DR. Tumor recurrence after complete resection for non-small cell lung cancer. The Annals of thoracic surgery. 2012; 93(6):1813-1820; discussion 1820-1811.

19. Higgins KA, Chino JP, Ready N, D'Amico TA, Berry MF, Sporn T, Boyd J and Kelsey CR. Lymphovascular invasion in non-small-cell lung cancer: implications for staging and adjuvant therapy. Journal of thoracic oncology : official publication of the International Association for the Study of Lung Cancer. 2012; 7(7):1141-1147.
20. Mitsudomi T, Hamajima N, Ogawa M and Takahashi T. Prognostic significance of p53 alterations in patients with non-small cell lung cancer: a meta-analysis. Clinical cancer research : an official journal of the American Association for Cancer Research. 2000; 6(10):4055-4063.

21. Wang YC, Lin RK, Tan YH, Chen JT and Chen CY. Wildtype p53 overexpression and its correlation with MDM2 and p14ARF alterations: an alternative pathway to nonsmall-cell lung cancer. Journal of clinical oncology : official journal of the American Society of Clinical Oncology. 2005; 23(1):154-164.

22. Kim JY, Kim HS, Lee S and Park JH. The expression of GLTSCR2, a candidate tumor suppressor, is reduced in seborrheic keratosis compared to normal skin. Pathology, research and practice. 2010; 206(5):295-299.

23. Dai MS, Shi D, Jin Y, Sun XX, Zhang Y, Grossman SR and Lu H. Regulation of the MDM2-p53 pathway by ribosomal protein L11 involves a post-ubiquitination mechanism. The Journal of biological chemistry. 2006; 281(34):2430424313.

24. Lohrum MA, Ludwig RL, Kubbutat MH, Hanlon M and Vousden KH. Regulation of HDM2 activity by the ribosomal protein L11. Cancer cell. 2003; 3(6):577-587.

25. Zhang Y, Wolf GW, Bhat K, Jin A, Allio T, Burkhart WA and Xiong Y. Ribosomal protein L11 negatively regulates oncoprotein MDM2 and mediates a p53-dependent ribosomal-stress checkpoint pathway. Molecular and cellular biology. 2003; 23(23):8902-8912.

26. Chen D, Zhang Z, Li M, Wang W, Li Y, Rayburn ER, Hill DL, Wang $\mathrm{H}$ and Zhang R. Ribosomal protein $\mathrm{S} 7$ as a novel modulator of p53-MDM2 interaction: binding to MDM2, stabilization of $\mathrm{p} 53$ protein, and activation of $\mathrm{p} 53$ function. Oncogene. 2007; 26(35):5029-5037.

27. Zhang Y and Lu H. Signaling to p53: ribosomal proteins find their way. Cancer cell. 2009; 16(5):369-377.

28. Bursac S, Brdovcak MC, Pfannkuchen M, Orsolic I, Golomb L, Zhu Y, Katz C, Daftuar L, Grabusic K, Vukelic I, Filic V, Oren M, Prives C and Volarevic S. Mutual protection of ribosomal proteins L5 and L11 from degradation is essential for p53 activation upon ribosomal biogenesis stress. Proceedings of the National Academy of Sciences of the United States of America. 2012; 109(50):20467-20472.

29. Xiong X, Zhao Y, He H and Sun Y. Ribosomal protein S27like and S27 interplay with p53-MDM2 axis as a target, a substrate and a regulator. Oncogene. 2011; 30(15):17981811.

30. Travis WD, Brambilla E, Mueller-Hermelink HK, Harris $\mathrm{CC}$ and editors. Tumours of the lung, pleura, thymus and heart. Lyon: IARC Press;. 2004.

31. Sobin LH, Gospodarowicz MK and Wittekind C. TNM classification of malignant tumours (UICC international union against cancer). 7th ed Chichester: John Wiley \& Sons;. 2009. 
32. Okamura K, Harada T, Wang S, Ijichi K, Furuyama K, Koga T, Okamoto T, Takayama K, Yano T and Nakanishi $\mathrm{Y}$. Expression of TrkB and BDNF is associated with poor prognosis in non-small cell lung cancer. Lung Cancer. 2012; 78(1):100-106.

33. Saeki H, Kitao H, Yoshinaga K, Nakanoko T, Kubo N, Kakeji Y, Morita M and Maehara Y. Copy-neutral loss of heterozygosity at the p53 locus in carcinogenesis of esophageal squamous cell carcinomas associated with p53 mutations. Clinical cancer research : an official journal of the American Association for Cancer Research. 2011; 17(7):1731-1740.

34. Egashira A, Morita M, Kakeji Y, Sadanaga N, Oki E, Honbo T, Ohta M and Maehara Y. p53 gene mutations in esophageal squamous cell carcinoma and their relevance to etiology and pathogenesis: results in Japan and comparisons with other countries. Cancer science. 2007; 98(8):11521156. 